\title{
A New High Precision Power Detector of Complex Voltage Signals
}

\author{
Predrag B. Petrović \\ Faculty of Technical Sciences, University of Kragujevac, Svetog Save, No. 65, 32000, Čačak, Serbia, \\ e-mail: predrag.petrovic@ftn.kg.ac.rs
}

\begin{abstract}
A current-mode bipolar power detector based on a novel synthesis of translinear loop squarer/divider is presented. The circuits consist of a single multiple-output current controlled current differencing transconductance amplifier (MO-CCCDTA), two current controlled conveyors (CCCII), and one resistor and one capacitor that are both grounded. The errors related to the signal processing and errors bound were investigated and presented in the paper. The PSpice simulation and experimental results are depicted, and agree well with the theoretical anticipation. The measurement results show that the scheme improves the accuracy of the detector to better than $0.04 \%$ and wide operating frequency range from $50 \mathrm{~Hz}$ to $10 \mathrm{MHz}$. The maximum power consumption of the detector is approximately $5.80 \mathrm{~mW}$, at $\pm 1.2 \mathrm{~V}$ supply voltages.
\end{abstract}

Keywords: RMS-to-DC converter, current-mode processing, current-controlled amplifier, current controlled conveyor, simulation.

\section{INTRODUCTION}

$\mathrm{T}$ HE POWER (RMS) measurement device is widely used in electrical engineering for different purposes such as instrumentation devices [1]. The RMS value of the voltage or current is the effective energy transferred to a load by a periodic source. Generally, RMS power detection is more useful than peak power detection, as the former represents a consistent standard way to measure and compare dynamic signals independent of the waveform shape. Detectors intended for this purpose need to involve wide bandwidth, high input impedance, low loss, low noise, and are expected to be compact and robust in the presence of process-voltage-temperature (PVT) variations. High dynamic range and low power consumption are also desirable.

Different methods have been reported for the precision measuring of the RMS value of an AC voltage, such as sampling [2], Monte Carlo [3] and the wavelet transform $[4,5]$. The implicit RMS converter described in [6-9] has been used for many years. Most of these devices are similarly comprised of two main parts: a full-wave rectifier (or absolute-value) circuit and a multiplier/divider circuit employing a log-antilog principle. High-frequency performances of these devices are limited to less than $5 \mathrm{MHz}$ due to the band-width and the slow rate of the fullwave rectifier. Design techniques based on bipolar dynamic trans-linear circuits were proposed to implement true RMSto-DC converters $[10,11]$. Although these schemes require only NPN transistors, their circuits are operated in only one quadrant and employ the full-wave rectifier. A new design technique for RMS-to-DC converter relies on the dual translinear-based squarer circuit proposed in $[12,13]$, where the input current can be a two-quadrant current signal. Given that the full-wave rectifier is not required within this conversion scheme, the circuit exhibits a wide bandwidth, which, due to the input interference, still appears limited compared to thermal-based or diode-based detectors [14]. Presently, there is a growing interest in synthesizing the current-mode circuits because of a number of their potential advantages such as larger dynamic range, higher signal bandwidth, greater linearity, simpler circuitry and lower power consumption.

This paper presents the principles of operation, and the detailed circuit design of the new current-mode realization of the bipolar RMS detector. The proposed detector uses an implicit computation to calculate the RMS value of an input signal, similarly to the translinear principle. The fundamental building block is an analogue multiplier/divider realized with one MO-CCCDTA, the anticipated exploitation of the proposed circuit being extended up to 10 $\mathrm{MHz}$, with increased linearity and precision in determining the effective value. Unlike the detector described in [15], which was realized using the CMOS technology, the one described in this paper involves simpler and more accurate control structure. Besides that, the proposed circuit does not require a more precise bias voltage realization and complex transistor pairing, which was typical of the realizations described in [15]. Additionally, it has fewer active building blocks and allows a faster access to the required feedback the RMS of the input signal which is the subject of processing. In addition, the circuit involves two grounded passive components (resistor and capacitor), rendering it very suitable for the IC implementation. The PSpice simulation and experimental results are also shown, and they are in agreement with theoretical analysis.

To gain a better insight into the technique proposed here, a comparison was made between results of this work and measurement results of the formerly reported RMS-DC converters. Table 1. summarizes this comparison by showing some important parameters of the proposed converters. The frequency responses, dynamic range of this bipolar detector, were all comparable and even superior to most diode detectors. The error in computing the effective value of the processed input voltage signal was lower than in all realizations used for comparisons, whereby the circuit of the proposed detector, which includes a wider dynamic 
range, is more facilitating for the realization compared to those described in $[15,24-26,32]$. Similarly, it does not require a specific compensation procedure as [27]. The detectors realized in CMOS technology offer a wider frequency range and lower power consumptions then the proposed RMS detector, but often demand narrow current or voltage range of the input signals.

Table 1. Comparison of performance of different RMS converters.

\begin{tabular}{|c|c|c|c|c|c|c|}
\hline Ref. & $\begin{array}{c}\text { Type of active } \\
\text { building blocks } \\
\text { used }\end{array}$ & $\begin{array}{l}\text { Dyn. } \\
\text { range }\end{array}$ & $\begin{array}{c}\text { Max. } \\
\text { frequency }\end{array}$ & $\begin{array}{c}\text { Max. } \\
\text { amplitude }\end{array}$ & $\begin{array}{c}\text { Relative } \\
\text { error }\end{array}$ & $\begin{array}{c}\text { Power } \\
\text { consump. }\end{array}$ \\
\hline [15] & $\begin{array}{l}\text { DO-CCII, } 3 \\
\text { OA, } 3 \\
\text { MOSFET }\end{array}$ & $24 \mathrm{~dB}$ & $1 \mathrm{MHz}$ & $1 \mathrm{~V}$ & $0.05 \%$ & $18.8 \mathrm{~mW}$ \\
\hline [16] & $\begin{array}{l}\text { SOI CMOS, } \\
\text { Schottky diode, } \\
\text { decoder }\end{array}$ & $13 \mathrm{~dB}$ & $\begin{array}{c}30-50 \\
\mathrm{GHz}\end{array}$ & $100 \mathrm{mV}$ & N/A & $24 \mathrm{~mW}$ \\
\hline [17] & $\begin{array}{l}\text { BJT current- } \\
\text { mode squarer, } \\
\text { averaging and } \\
\text { square root } \\
\text { circuits }\end{array}$ & $20 \mathrm{~dB}$ & $\begin{array}{l}700 \mathrm{kHz}- \\
10 \mathrm{MHz}\end{array}$ & $1 \mathrm{~mA}$ & $0.1 \%$ & $<15 \mathrm{~mW}$ \\
\hline [18] & $\begin{array}{c}\text { CMOS } \\
\text { squarer/divider } \\
\text { and LPF }\end{array}$ & $11 \mathrm{~dB}$ & N/A & $30 \mu \mathrm{A}$ & $3 \%$ & $100 \mu \mathrm{W}$ \\
\hline [19] & $\begin{array}{c}\text { UWB CMOS, } \\
\text { OA, level } \\
\text { shifter }\end{array}$ & $20 \mathrm{~dB}$ & $\begin{array}{c}125 \\
\text { MHz- } 8.5 \\
\text { GHz }\end{array}$ & N/A & $1.12 \%$ & $0.18 \mathrm{~mW}$ \\
\hline [20] & $\begin{array}{c}\text { BiCMOS } 2 \mathrm{TL}, \\
2 \mathrm{~V} / \mathrm{I} \\
\text { converters }\end{array}$ & $40 \mathrm{~dB}$ & $1.3 \mathrm{GHz}$ & $100 \mathrm{mV}$ & $1 \%$ & N/A \\
\hline [21] & $\mathrm{DA}, \log \mathrm{A}, \mathrm{OA}$ & $22 \mathrm{~dB}$ & $\begin{array}{c}500 \\
\mathrm{MHz}-2 \\
\mathrm{GHz}\end{array}$ & $6 \mathrm{~V}$ & $1.26 \%$ & N/A \\
\hline [22] & $\begin{array}{c}\text { BiCMOS } \\
\text { Meyer detector }\end{array}$ & $40 \mathrm{~dB}$ & $20 \mathrm{GHz}$ & $50 \mathrm{mV}$ & $1.12 \%$ & N/A \\
\hline [23] & $\begin{array}{l}2 \text { CCII, } 2 \mathrm{~N}+1 \\
\text { MOSFETs }\end{array}$ & N/A & $10 \mathrm{MHz}$ & $500 \mathrm{mV}$ & $>1 \%$ & N/A \\
\hline [24] & $\begin{array}{c}\text { Squarer/divider, } \\
3 \mathrm{OA}\end{array}$ & $20 \mathrm{~dB}$ & $8 \mathrm{MHz}$ & $3 \mathrm{~V}$ & $0.5 \%$ & $33 \mathrm{~mW}$ \\
\hline [25] & $\begin{array}{c}\text { SRD } \\
\text { transconductor, } \\
\text { LPF, MOS TL }\end{array}$ & N/A & $10 \mathrm{kHz}$ & $20 \mu \mathrm{A}$ & $2 \%$ & N/A \\
\hline [26] & $\begin{array}{c}2 \text { CCII, } 2 \\
\text { diodes, } \\
\text { CMOS current }\end{array}$ & $15 \mathrm{~dB}$ & $1 \mathrm{MHz}$ & $300 \mathrm{mV}$ & $1 \%$ & N/A \\
\hline [27] & $\begin{array}{c}\text { sources, } \\
\text { reference } \\
\text { sources, LPF }\end{array}$ & N/A & $\begin{array}{c}0.2-0.8 \\
\mathrm{GHz}\end{array}$ & $2.3 \mathrm{~V}$ & $1.07 \%$ & $3.36 \mathrm{~mW}$ \\
\hline [28] & $\begin{array}{l}\text { RF PD, LimA, } \\
\text { LogA }\end{array}$ & $50 \mathrm{~dB}$ & $\begin{array}{l}0.5-3 \\
\mathrm{GHz}\end{array}$ & $1 \mathrm{~V}$ & N/A & $0.9 \mathrm{~mW}$ \\
\hline [29] & $\begin{array}{l}\text { RF PD, LNA, } \\
\text { PA, CM, LPF }\end{array}$ & $20 \mathrm{~dB}$ & $2.4 \mathrm{GHz}$ & $200 \mathrm{mV}$ & $2 \%$ & $10 \mathrm{~mW}$ \\
\hline [30] & $\begin{array}{c}\text { CMOS } \\
\text { squaring } \\
\text { circuits, four } \\
\text { current mirrors }\end{array}$ & $12 \mathrm{~dB}$ & $\begin{array}{c}95 \mathrm{MHz} \\
\left(\mathrm{I}_{\mathrm{in}}=1 \mathrm{~mA}\right) \\
66 \mathrm{MHz} \\
\left(\mathrm{I}_{\mathrm{in}}=500 \mu\right. \\
\mathrm{A})\end{array}$ & $1500 \mu \mathrm{A}$ & $<2 \%$ & $6.04 \mathrm{nW}$ \\
\hline [31] & $\begin{array}{c}\text { CMOS } \\
\text { squarer/divider } \\
\text { and LPF }\end{array}$ & $28 \mathrm{~dB}$ & N/A & $400 \mathrm{nA}$ & $1.5 \%$ & $1.5 \mu \mathrm{W}$ \\
\hline [32] & $\begin{array}{l}\text { MTL-based } \\
\text { squaring } \\
\text { circuit, LPF, } \\
\text { square-rooting } \\
\text { circuit }\end{array}$ & N/A & $2 \mathrm{MHz}$ & $390 \mu \mathrm{A}$ & $3 \%$ & $2 \mathrm{~mW}$ \\
\hline $\begin{array}{l}\text { This } \\
\text { work }\end{array}$ & $\begin{array}{l}\text { CDTA, } 2 \\
\text { CCCII }\end{array}$ & $36 \mathrm{~dB}$ & $10 \mathrm{MHz}$ & $500 \mathrm{mV}$ & $0.04 \%$ & $5.80 \mathrm{~mW}$ \\
\hline
\end{tabular}

\section{PROPOSED DETECTOR CIRCUITS}

The proposed current-mode RMS detector using the MOCCCDTA and MO-CCCIIs [33] is shown in Fig.1. MOCCCDTA properties are similar to conventional CDTA, except for the fact that input voltages of MO-CCCDTA are not zero and the MO-CCCDTA has finite input resistances $R_{p}$ and $R_{n}$ at the $p$ and $n$ input terminals, respectively. These parasitic resistances are equal and can be controlled by the bias current $I_{P}, R_{p}=R_{n}=V_{T} /\left(2 I_{P}\right)$ (Fig.3.), where $V_{T}=$ $26 \mathrm{mV}$ at $27^{\circ} \mathrm{C}$ is the usual thermal voltage given by $k T / q$, $k=$ Boltzmann's constant $=1.38 \times 10^{-23} \mathrm{~J} / \mathrm{K}, \quad T=$ absolute temperature (in Kelvin), and $q=1.6 \times 10^{-19}$ C. In [34], confirmation is given of linear dependence of input resistances $R_{p}$ and $R_{n}$ on the bias current $I_{\mathrm{p}}$, in the range between $0.1 \mu \mathrm{A}$ and $1000 \mu \mathrm{A}$, over a wide temperature range. These resistances can be independently controlled in this scenario, however, the input rate of MO-CCCDTA becomes much more complex for implementation. In addition to this, in the proposed detector circuit this rate is operated in the current mode, so that there is no special need for their controllability from the aspect of improving the convertor's performance. In the case of processing current input signals, voltage to current converter in the proposed power detector circuits is not required (MO-CCCII in Fig.1.) and the realization is consequently much simpler.

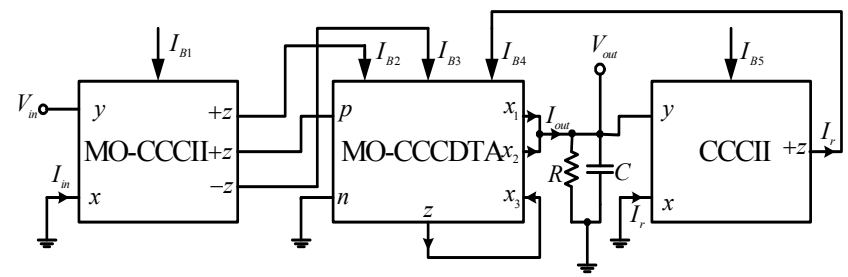

Fig.1. The proposed RMS circuit.

Using the standard notation for the MO-CCCDTA, the circuit is characterized by the following constitutive equations (Fig.2.a)) [34]:

$$
v_{p}=v_{n}=0 ; i_{z}=i_{p}-i_{n} \text {, and } i_{x}=g_{m} v_{z}=g_{m} Z_{z} i_{z}
$$

where $p$ and $n$ are input terminals, $z$ and $\pm x$ are output terminals, $g_{m}$ is the transconductance gain, and $Z_{z}$ is external impedance connected at the terminal $z$. Based on the expressions above, the current flow out of the terminal $z\left(i_{z}\right)$ is a difference between the input currents through the terminals $p$ and $n\left(i_{p}-i_{n}\right)$. The voltage drop at the terminal $z$ is transferred to the current at the terminal $x\left(i_{x}\right)$ by a transconductance gain $\left(g_{m}\right)$ of the CDTA. These currents, which are copied to a general number of output current terminals $x$, are equal in magnitude, but flow in opposite directions. From the point of view of $i_{p}, i_{n}$ and $i_{x}$, currents, the circuit operates as a current-mode amplifier. Its gain is given by the product of external impendence and internal transconductance. When the $z$-terminal voltage is maintained within relatively low levels, the circuit operation approaches the ideal current mode.
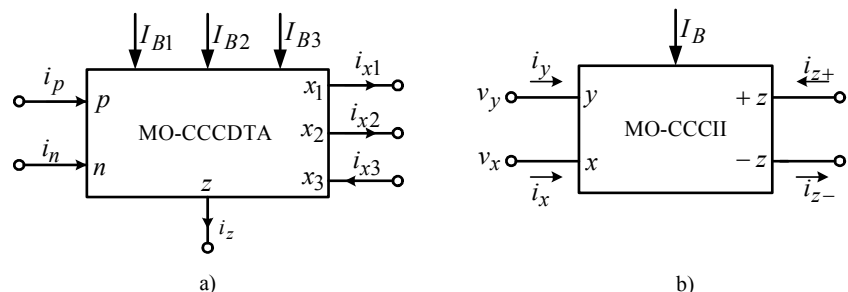

Fig.2. Electrical symbols of MO-CDTA and MO-CCCII.

Although there are several techniques to realize the CDTA, one of the possible bipolar realizations is shown in Fig.3. [35]. 


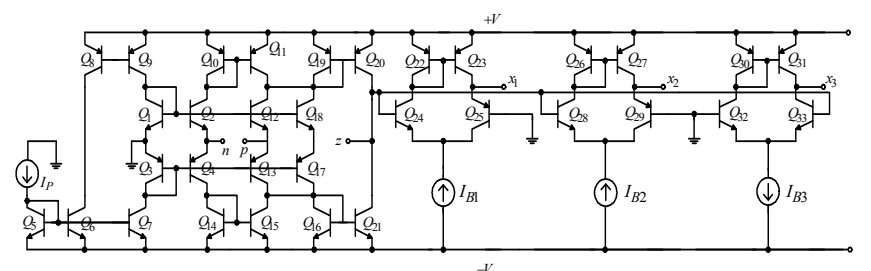

Fig.3. Bipolar realization of MO-CCCDTA.

It mainly consists of a current-differencing circuit formed by two current followers, a basic current mirror and multiple-output transconductance amplifier. In this case, the transconductance gain $g_{m}$ of the CDTA is directly proportional to the external bias current $I_{B}$ (three bias currents $I_{B 2}, I_{B 3}$ and $I_{B 4}$ in case of the converter circuits proposed here, Fig.1.), which can be written by:

$$
g_{m}=\frac{I_{B}}{2 V_{T}}
$$

At the circuit shown in Fig.1. the outputs of MO-CCCII and CCCII are directly driving bias inputs of the CCCDTA, which has been also used in certain realizations based on the use of CDTA [36-39] which have been confirmed thus far. This approach induces no problems in BJT operation, i.e. it does not affect their working regime due to the fact that the bias currents introduced in this manner are used to define the value of the transconductance gains. This has been confirmed by the recorded DC transfer characteristics of these realizations.

Generally, a MO-CCCII is a multiple-terminal active building block, as shown in Fig.1. The port relations of the MO-CCCII (Fig.2.b)) can be presented by the following equation:

$$
i_{y}=0 ; v_{x}=v_{y}+i_{x} R_{x} ; i_{z+}=+i_{x} ; i_{z-}=-i_{x}
$$

The electrical symbol of the MO-CCCII is shown in Fig.2.b), while the schematic bipolar realization is shown in Fig.4. In this case, the input resistance $R_{x}$ at the terminal $x$ can be expressed by:

$$
R_{x}=\frac{V_{T}}{2 I_{B}}
$$

where $V_{T}$ is the thermal voltage and $I_{B}\left(I_{B 1}\right.$ and $I_{B 5}$ in the proposed realization, Fig.1.) is the bias current of the conveyor which is tunable over several decades [40-42].

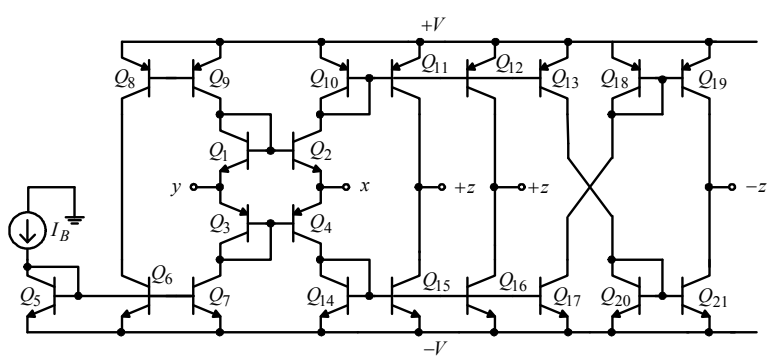

Fig.4. Bipolar realization of MO-CCCII.
By the routine analysis of the proposed RMS circuit shown in Fig.1. and using the properties of MO-CCCDTA and MO-CCCII, the output current at $z$ terminal of MOCCCDTA is obtained by:

$$
I_{z}=I_{\text {in }}=I_{x 3}
$$

The output voltage at $z$ terminal $\left(V_{z}\right)$ of MO-CCCDTA equals:

$$
V_{z}=\frac{I_{x 3}}{g_{m 3}}=\frac{2 V_{T} I_{i n}}{I_{r}}
$$

Fig.1. infers that $I_{B 2}=I_{i n}, I_{B 3}=-I_{i n}$, and $I_{B 4}=I_{r}$. Thus, the $I_{x 1}$ and $I_{x 2}$ can be obtained by:

$$
\begin{gathered}
I_{x 1}=\left\{\begin{array}{c}
g_{m 1} V_{z}=\frac{I_{\text {in }}^{2}}{I_{r}} \text { if } I_{\text {in }} \succ 0 \\
0 \text { if } I_{\text {in }} \prec 0
\end{array}\right. \\
I_{x 2}=\left\{\begin{array}{c}
0 \text { if } I_{\text {in }} \succ 0 \\
g_{m 2} V_{z}=\frac{I_{\text {in }}^{2}}{I_{r}} \text { if } I_{\text {in }} \prec 0
\end{array}\right.
\end{gathered}
$$

The above equation defines the output current $I_{\text {out }}$ as:

$$
I_{\text {out }}=I_{x 1}+I_{x 2}=\frac{I_{\text {in }}^{2}}{I_{r}}==\frac{R_{x 2}}{R_{\text {in }}^{2}} \frac{V_{\text {in }}^{2}}{V_{\text {out }}}
$$

where $R_{\text {in }}=R_{x I}$. The current $I_{\text {out }}$ is then converted to the output voltage, $V_{\text {out }}$, with an implied low-pass filtering function. We can recognize that the output current-tovoltage conversion (with second CCCII) establishes a differential equation relating the current, $I_{\text {out }}$, to the output voltage, $V_{\text {out }}$, i.e. [43]:

$$
\dot{V}_{\text {out }}(t)+\omega_{0} V_{\text {out }}(t)=\frac{1}{C} I_{\text {out }}(t) ; \omega_{0}=\frac{1}{R C}
$$

A simple way to obtain this equation is to determine the transfer function relating $I_{\text {out }}$ to $V_{\text {out }}$, and then take this back to the time domain. Equation (9) is the generic time-domain description of a low-pass filter, where the coefficient of the undifferentiated term on the LHS of the equation equals the filter cut-off frequency. Equation (8) can subsequently be combined with the above to obtain:

$$
\dot{V}_{\text {out }}(t)+\omega_{o} V_{\text {out }}(t)=\frac{1}{R_{1} C} \frac{V_{\text {in }}^{2}(t)}{V_{\text {out }}(t)} ; \quad R_{1}=\frac{R_{\text {in }}^{2}}{R_{x 2}}
$$

We may now multiply both sides of the equation by $2 V_{\text {out }}$ and make a simple observation incorporated into the final result:

$$
\begin{aligned}
& 2 V_{\text {out }}(t) \dot{V}_{\text {out }}(t)+2 \omega_{o} V_{\text {out }}^{2}(t)=\frac{2}{R_{1} C} V_{\text {in }}^{2}(t) \Rightarrow \\
& \frac{d}{d t}\left(V_{\text {out }}^{2}(t)\right)+2 \omega_{o}\left(V_{\text {out }}^{2}(t)\right)=\frac{2}{R_{1} C} V_{\text {in }}^{2}(t)
\end{aligned}
$$


Equation (11) is a first-order differential equation relating $\left(V_{\text {out }}\right)^{2}$ and $\left(V_{\text {in }}\right)^{2}$, having the same form as (9). Therefore, the square of the output is a low-pass filtered version of the square of the input. Based on (11), we can assume that:

$$
V_{\text {out }}^{2}(t)=\frac{2}{R_{1} C} \int_{0}^{t} e^{-2 \omega_{0}(t-\tau)} V_{\text {in }}^{2}(\tau) d \tau
$$

The equation above (convolution integral) implies that if the square root of both sides is considered, the output is the root mean square of the input voltage, where the integral is assumed to compute mean value function. The implied filtering function is given by:

$$
H(s)=\frac{R}{R_{1}} \frac{\omega_{3 d b}}{s+\omega_{3 d b}} \text {, where } \omega_{3 d b}=\frac{2}{R C}
$$

The low-pass filter performs averaging of the RMS function and needs to be of a lower corner frequency than the lowest frequency of interest. For line frequency measurements, this filter is simply too large to implement on-chip, but the proposed detector requires only one capacitor on the output to implement the low-pass filter. This capacitor can be selected by the user, depending on frequency range and settling time requirements. Low-pass filtering of the square of the input sine functions with some amplitude $V$, frequency $f$, and phase shift $\phi,\left(V_{i n}(\mathrm{t})=\right.$ $V \cos (\omega t+\phi))$, as suggested by (11), yields a time function $y(t)$ given by:

$$
y(t)=\frac{V^{2}}{2}\left(1+\frac{1}{\sqrt{1+\left(2 \omega / \omega_{3 d b}\right)^{2}}} \cos (2 \omega t)\right)=V_{\text {out }}^{2}(t)
$$

As an example, time functions, defined by equations (12) and (14), with amplitude and frequency of an input signal of $1 \mathrm{~V}$ and $50 \mathrm{~Hz}$, respectively, and $\omega_{0}=100 \mathrm{rad} / \mathrm{s}$ are shown in Fig.5. As for the RMS value and output signal ripple $V_{\text {out }}(t)$ (upon vanishing of the transients), both functions are equivalent. The input phase shift, such as the net phase shift, after filtering of the second harmonic, yields zero phase, thereby simplifying the form of $y(t)$ without losing generality. $R / R_{l}$ was set to unity for simplicity reasons.

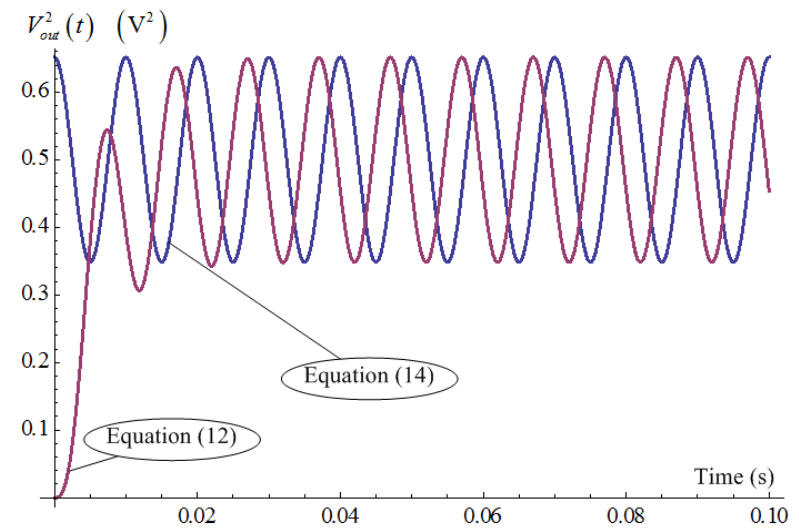

Fig.5. Time functions defined by equations (12) and (14).
If we assume that the input signal frequency is considerably higher than the filter cut-off frequency, the approximate final output can be rather successfully estimated with just a few terms of a Taylor series. Accordingly, the DC component of the output voltage of the proposed circuit, i.e. the apparent output RMS value of the input and the associated second-harmonic component of the output voltage resulting from the rapidly decreasing magnitudes of higher harmonic terms, such as the ripple (peak-to-peak ripple of the output), is expressed as:

$$
\begin{aligned}
& V_{R M S} \approx\left[1-\frac{1 / 16}{1+\left(2 \omega / \omega_{3 d b}\right)^{2}}\right] V_{\text {true }-R M S} \\
& V_{\text {ripple }} \approx \frac{1 / 2}{\sqrt{1+\left(2 \omega / \omega_{3 d b}\right)^{2}}} V_{\text {true }-R M S}
\end{aligned}
$$

The equation above infers the accuracy associated with the proposed circuit for measuring the effective value of the input sine voltage signal. In case of the input signal described by the Fourier order (Appendix), the estimation defined by (15) gains in complexity, but it clearly implies that it is possible to filter and single out the effective value of the signal processed in respective way.

\section{NON-IDEAL SYSTEM ANALYSIS}

The effects of MO-CCCDTA and MO-CCCII nonidealities on the RMS detector performance are to be considered in this section. By considering the non-ideal MO-CCCII characteristics, equation (3) can be rewritten as:

$$
i_{y}=0 ; v_{x}=\alpha v_{y}+i_{x} R_{x} ; i_{z+}=+\beta_{p} i_{x} ; i_{z-}=-\beta_{n} i_{x}
$$

where $\alpha=1-\varepsilon_{v}$ and $\varepsilon_{v}\left(\left|\varepsilon_{v}\right|<<1\right)$ represents the voltage tracking error from $y$ to $x$ terminal, $\beta_{p}=1-\varepsilon_{p}$ and $\varepsilon_{p}\left(\left|\varepsilon_{p}\right|<<1\right)$ denotes the current tracking error from $x$ to $+z$ terminal, while $\beta_{n}=1-\varepsilon_{n}$ and $\varepsilon_{n}\left(\left|\varepsilon_{n}\right|<<1\right)$ stand for the current tracking error from $x$ to $-z$ terminal of the MO-CCCII, respectively. Given the non-idealities, currents generated from first and second CCCIIs (first and third circuits of the proposed realization in Fig.1.) can be defined as:

$$
I_{\text {in }}=\frac{\alpha_{1} V_{\text {in }}}{R_{x 1}} ; i_{p}=I_{B 2}=\frac{\beta_{p 1} \alpha_{1} V_{\text {in }}}{R_{x 1}} ; I_{B 3}=\frac{\beta_{n 1} \alpha_{1} V_{\text {in }}}{R_{x 1}} ; I_{r}=\frac{\beta_{p 2} \alpha_{2} V_{\text {out }}}{R_{x 2}}
$$

In practice, the deviation from the ideal performance of the proposed RMS circuits is mainly due to the non-ideal CCCDTA characteristics, which can be divided into two categories, i.e. parasitic gain effects and parasitic impedance effects. Fig.6. illustrates the simplified equivalent circuit represented by the behavior of the non-ideal CCCDTA.

A practical CCCDTA device can be modeled as an ideal CCCDTA with finite parasitic resistances and capacitances, as well as non-ideal current transfer gains and a transconductance inaccuracy factor of the CCCDTA. Fig.6. shows a more sophisticated circuit model to represent the non-ideal CCCDTA device, where $R_{p}, R_{n}, R_{x}$, and $R_{z}$ are the terminal parasitic resistances. $R_{p}$ and $R_{n}$ are the currentcontrollable parasitic resistances, where $R_{x}$ and $R_{z}$, as typical 
values of the parasitic resistances, connected to the terminals $x$ and $z$, respectively, are in the range of several mega-ohms. $C_{x}$ and $C_{z}$ are the terminal parasitic capacitances from terminals $x$ and $z$ to the ground (the shunt output impedances $\left(R_{z} / / C_{z}\right.$ and $\left.R_{x} / / C_{x}\right)$ at terminals $z$ and $x$, respectively). Typically, these parasitic capacitances are in the order of several pFs. In Fig.6., $\alpha_{p}$ represents the non-ideal current transfer gain from the $p$ terminal to the $z$ terminal of the CCCDTA, $\alpha_{n}$ denotes the non-ideal current transfer gain from the $n$ terminal to the $z$ terminal of the CCCDTA, and $\beta$ is the transconductance inaccuracy factor from the $z$ terminal to the $x$ terminal of the CCCDTA. The typical values of the non-ideal current transfer gains and the transconductance inaccuracy factor $\alpha_{n}, \alpha_{p}$, and $\beta$ range from 0.9 to 1 , with an ideal value of 1 .

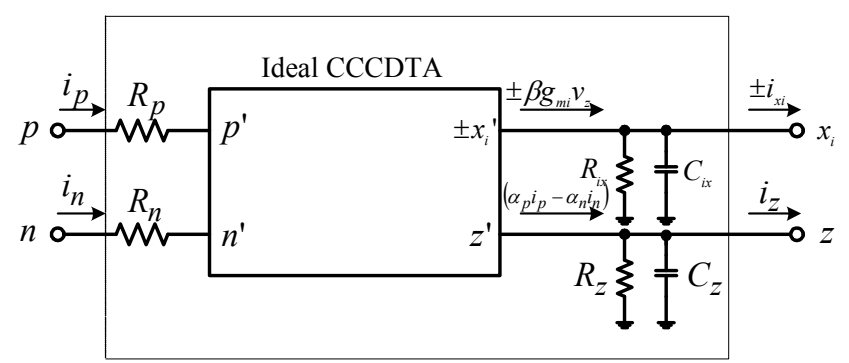

Fig.6. The equivalent circuit of the non-ideal CCCDTA.

Based on the circuit representation in Fig.6. and the proposed RMS detector, and given the non-ideal CDTA characteristics, the application of the non-ideal equivalent circuit mode of the MO-CCCDTA to the proposed circuit results in tedious derivations yielding the following modified characteristic equation:

$$
\begin{gathered}
i_{p}=I_{B 2}=\frac{\alpha_{1} \beta_{p 1} V_{\text {in }}}{R_{x 1}} ; I_{B 3}=\frac{\alpha_{1} \beta_{n 1} V_{\text {in }}}{R_{x 1}} ; I_{r}=\frac{\alpha_{2} \beta_{p 2} V_{\text {out }}}{R_{x 2}}=I_{B 4} \\
V_{z}=\frac{R_{z}}{1+s R_{z} C_{z}}\left(\alpha_{p} i_{p}-\beta g_{m 3} V_{z}\right) \Rightarrow \\
V_{z}=\frac{\alpha_{p} R_{z}}{1+\beta g_{m 3} R_{z}+s R_{z} C_{z}} i_{p} ; g_{m 3}=\frac{I_{r}}{2 V_{T}}=\frac{\alpha_{2} \beta_{p 2} V_{\text {out }}}{2 V_{T} R_{x 2}}
\end{gathered}
$$

The modified output current for the proposed RMS detector can be rewritten as:

$$
\begin{aligned}
& I_{\text {out }}=\left\{\begin{array}{l}
\beta g_{m 1} V_{z} \frac{\frac{R_{1 x}}{1+s C_{1 x} R_{1 x}}}{\frac{R_{1 x}}{1+s C_{1 x} R_{1 x}}+\frac{R}{1+s C R}}=\beta g_{m 1} V_{z} \frac{R_{1 x}(1+s C R)}{R_{1 x}(1+s C R)+R\left(1+s C_{1 x} R_{1 x}\right.} ; V_{i n} \succ 0 \\
\beta g_{m 2} V_{z} \frac{\frac{R_{2 x}}{1+s C_{2 x} R_{2 x}}}{\frac{R_{2 x}}{1+s C_{2 x} R_{2 x}}+\frac{R}{1+s C R}}=\beta g_{m 2} V_{z} \frac{R_{2 x}(1+s C R)}{R_{2 x}(1+s C R)+R\left(1+s C_{2 x} R_{2 x} x\right.} ; V_{i n} \prec 0
\end{array}\right. \\
& g_{m 1}=\frac{I_{B 2}}{2 V_{T}} ; g_{m 2}=\frac{I_{B 3}}{2 V_{T}}
\end{aligned}
$$

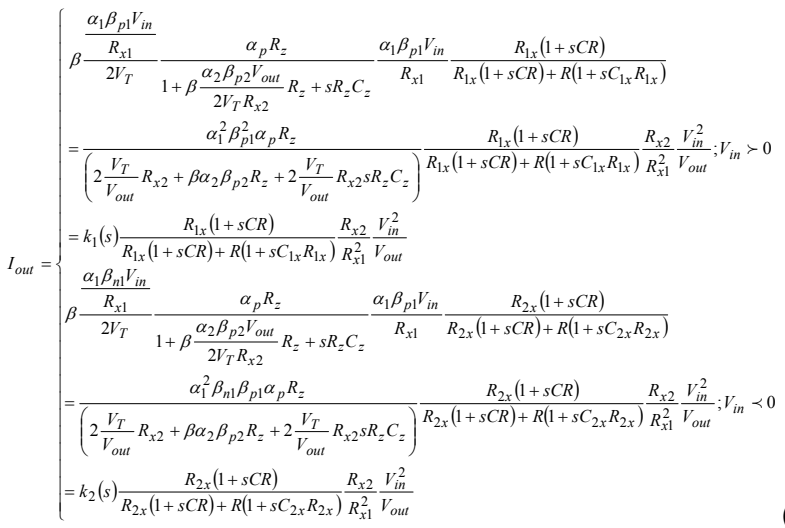

where:

$$
\begin{aligned}
& k_{1}(s)=\frac{\alpha_{1}^{2} \beta_{p 1}^{2} \alpha_{p} R_{z}}{\left(2 \frac{V_{T}}{V_{\text {out }}} R_{x 2}+\beta \alpha_{2} \beta_{p 2} R_{z}+2 \frac{V_{T}}{V_{\text {out }}} R_{x 2} s R_{z} C_{z}\right)} \\
& k_{2}(s)=\frac{\alpha_{1}^{2} \beta_{n 1} \beta_{p 1} \alpha_{p} R_{z}}{\left(2 \frac{V_{T}}{V_{\text {out }}} R_{x 2}+\beta \alpha_{2} \beta_{p 2} R_{z}+2 \frac{V_{T}}{V_{\text {out }}} R_{x 2} s R_{z} C_{z}\right)}
\end{aligned}
$$

The expressions above infer that the deviations in the transfer current gains are mainly due to the parasitic gains of the CDTAs. In order to improve the discrepancy to theoretical response, a high-performance CDTA with minor parasitic effects need to be employed. However, easy compensation for these deviations is possible by adjusting the values of $I_{B 1}$ and $I_{B 5}$, respectively.

The DC component of the output signal (following the elimination of oscillations in the proposed circuit's response) has an inclination towards the following value:

$$
V_{\text {out }} \approx \frac{R R_{x 2} R_{z} V^{2} \alpha_{1}^{2} \alpha_{p} \beta \beta_{p 1}^{2}}{R_{x 1}^{2}\left(4 R_{x 2} V_{T}+\sqrt{2} R_{z} \alpha_{2} \beta_{p 2} V\right)}
$$

with no major divergences from $\mathrm{V} / \sqrt{2}$. Three parameters have a dominant impact on the calculated RMS value of the input voltage signal (based on (21)); $R, R_{\mathrm{x} 1}$ and $R_{\mathrm{x} 2}$. If their yields were to be taken into consideration, the calculation error order would be $3.8 \%$ (for an input sinus signal having an amplitude of $1 \mathrm{~V}$ i frequency of $50 \mathrm{~Hz}$ ). If the yields of these parameters were to be supplemented by yields $\alpha_{1}$ and $\beta_{p 1}$, the yields of all other parameters can be neglected. However, a proper evaluation of the possible error will be obtained only after conducting simulation checks from Section 4 of this paper, in order to be able to assess the measuring uncertainty of the proposed RMS detector.

The output voltage of the proposed RMS detector is defined as:

$$
V_{\text {out }}=\beta g_{m i} V_{z} \frac{R^{\prime}}{1+s C^{\prime} R^{\prime}} ; R^{\prime}=\frac{R R_{i x}}{R+R_{i x}} ; C^{\prime}=C+C_{i x} ; i=1,2 .
$$

Given the non-ideal characteristics of MO-CCCDTA and CCCIIs, the implied filtering function implies that: 


$$
H^{\prime}(s)=k_{i}(s) \frac{R^{\prime}}{R_{1}} \frac{\omega_{3 d b}^{\prime}}{s+\omega_{3 d b}^{\prime}} \text {, where } \omega_{3 d b}^{\prime}=\frac{2}{R^{\prime} C^{\prime}} ; i=1,2
$$

Equation (25) suggests that the filtering function, represented by the integral operators, equation (12), has different characteristics compared to the ideal situation, equation (13), especially in the operators' behavior at higher frequencies. For signals whose fundamental frequency is approximately five times the cutoff frequency of the output current to voltage converter, a much better average accuracy than $1 \%$ will be achieved.

\section{MEASUREMENT ERROR AND UNCERTAINTY ANALYSIS}

Equation (26) provides the definition of processingmeasurement error $e$ as the difference between RMS value of the output signal $V_{\text {out }}(t)$ and RMS value of the input signal $V_{i n}(t), V /$ sqrt (2) expressed in percentages as:

$$
e=\frac{\sqrt{\frac{1}{T} \int_{0}^{T} V_{\text {out }}^{2}(t) d t}-\frac{\sqrt{2}}{2} V}{\frac{\sqrt{2}}{2} V} 100(\%)=\left(\frac{\sqrt{\frac{1}{T} \int_{0}^{T} V_{\text {out }}^{2}(t) d t}}{\frac{\sqrt{2}}{2} V}-1\right) 100(\%)
$$

The square value of the output signal $V_{\text {out }}(t)$ is determined by (12) (after transients in $V_{\text {out }}(t)$ disappear). The exact value of RMS of the output signal is $\operatorname{sqrt}\left(R / R_{I}\right) \cdot V /$ sqrt (2). Hence, when $R_{I}=R$, the measurement error $e$ is zero, as well as the measurement uncertainty. Naturally, a certain amount of dispersion for values of $R_{l}$ and $R$ around their nominal values needs to be allowed. Consequently, neither error nor measurement uncertainty equals zero. A way to express the error is to consider the values of $R_{l}$ and $R$ as random quantities characterized by their PDFs (Probability Density Function). Therefore, the interval, having $2 \varepsilon$ width, around the nominal value $R_{0}$ of the resistance $R, R=R_{0}(1 \pm \varepsilon)$ needs to be defined and associated with a certain distribution, e.g., uniform distribution. Current value of $R$ is drawn out randomly from interval of possible values. The same is needed in $R_{l}$. Each pair of random values for $R$ and $R_{l}$ defines the particular error. Considerable drawing is required in order to fully understand the error characteristic.

Example 1. The probability distribution of an error can be experimentally obtained through the following steps: putting $R=R_{0}(1 \pm 0.05)$ and $R_{1}=R_{10}(1 \pm 0.05)$ (up to $5 \%$ deviation from their nominal values), assuming the uniform distribution in intervals for both $R_{1}$ and $R$, taking $R_{10}=R_{0}$, repeating the experiment $n$ times (the results shown in Fig.7. is for $n=10^{6}$ ), and successively calculating the error (Fig.7.).

Conclusion: For RMS measurement of an input signal by the proposed electronic circuits, where $R_{10}=R_{0}$, the measurement error is $e \approx 0.0 \%$ (mean value of error samples), associated with standard uncertainty of $u(e) \approx 2.0 \%$ (standard deviation of error samples).

Based on [44], the extended uncertainty of RMS measurement is standard uncertainty multiplied by proper coverage factor $k$.

Common choice for factor $k$ is to provide that the interval $(e \pm U)=e \pm k u(e)$ corresponds to a particular level of confidence, e.g., $95 \%$, assuming Normal distribution, $k \approx 2$, and the extended measurement uncertainty $U \approx 4.0 \%$.

However, Fig.7. clearly shows that the error distribution is triangular, not Normal, which implies that the coverage factor $k$ should be 1.9 and the extended measurement uncertainty $U \approx 3.9 \%$.

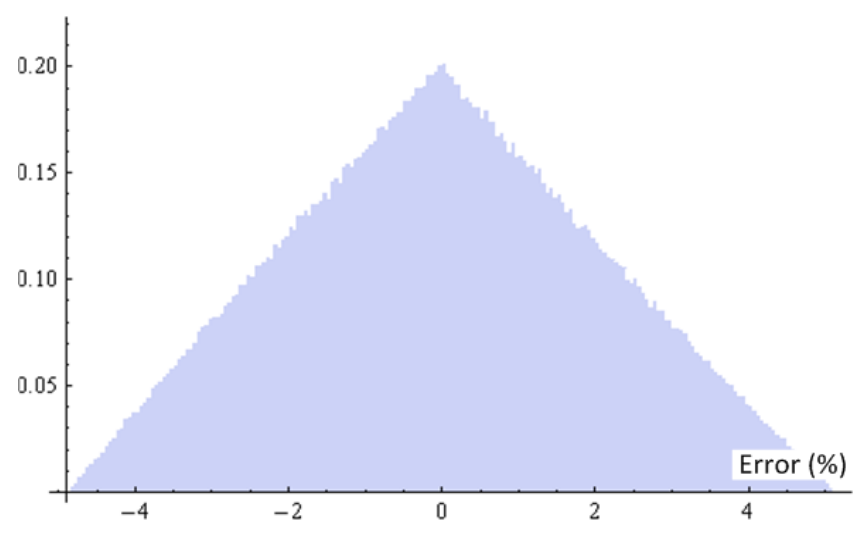

Fig.7. PDF of measurement error, for Example 1.

Based on [45], the Monte Carlo approach suggests (for the same level of confidence) calculating 2.5th and 97.5th percentiles, seeking the limits of an interval that contains $95 \%$ of all error samples. Calculated in this way, the extended uncertainty equals $U=\left(97.5^{\text {th }}\right.$ per. $-2.5^{\text {th }}$ per.) $/ 2 \approx 3.9 \%$.

Practically, all the applied methods give the same value of extended measurement uncertainty.

The identical method can be applied in non-ideal systems, the difference being in a more complex mathematical model which involves a lot of parameters, some of them being parasitic. The model was presented in the previous chapter.

Example 2. The method of estimating measurementprocessing error and corresponding uncertainty is presented when the input signal is $V_{i n}(t)=V \sin (2 \pi 50 t)$, and the parameters characterizing electronic circuits are as follows: $R=R_{x 1}=R_{x 2}=10(1 \pm 0.05) \mathrm{k} \Omega ; C=C_{z}=C_{l x}=C_{2 x}=$ $1(1 \pm 0.05) \mu \mathrm{F} ; R_{\mathrm{z}}=R_{l x}=R_{2 x}=1(1 \pm 0.05) \mathrm{M} \Omega ; \alpha_{1}=\alpha_{2}=\alpha_{p}=$ $\beta=\beta_{p 1}=\beta_{p 2}=\beta_{\mathrm{n} 1}=0.95$ to 1 . Each parameter is given as an interval of values, whereby the probability for any value in interval is assumed to be equal.

The samples of parameter values were chosen randomly from specified intervals and were mutually independent. A numerical experiment was performed $n$ times $\left(n=10^{5}\right)$. Experimenting with different values of $n$ can be suggested as suitable for statistical stability of result, given that uncertainties should be expressed with no more than two significant digits. The typical result of numerical experiment is given in Fig.8.

Measurement error $e$ is calculated as mean value of error samples, $e \approx-4.1 \%$, and standard uncertainty $u(e) \approx 4.0 \%$, as standard deviation of error samples [44]. Expanded uncertainty, for coverage factor $k=2$, is $U \approx 2 \times 4.0 \approx 8.0 \%$.

The Monte Carlo approach [45] gives the lower and upper limits of interval which contains $95 \%$ of error samples, i.e. $11.7 \%$ and $3.9 \%$, respectively, which results in approximately $7.8 \%$ uncertainty. 


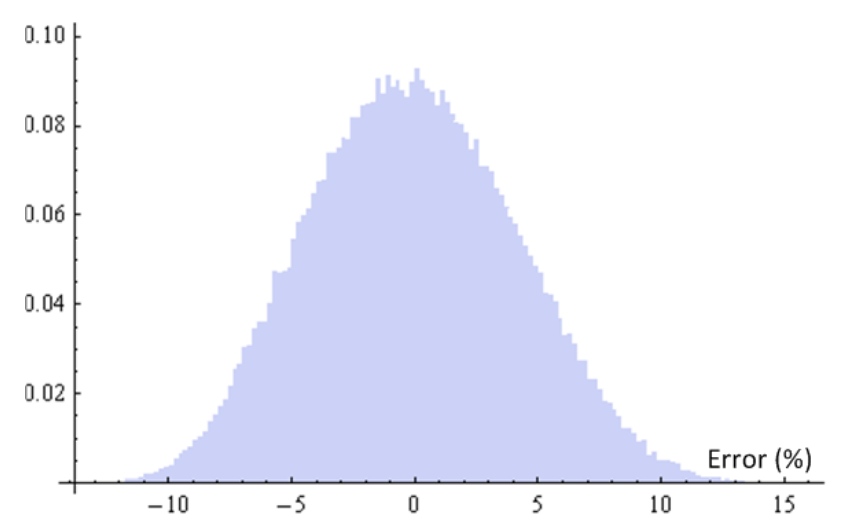

Fig.8. PDF of measurement error, for Example 2.

The mean value of error samples, $e \approx-4.1 \%$, indicates that the measuring system produces major systematic error of measurement, which can be anticipated, because although the parameter intervals are assumed to be fully arbitrary, its particular values affect the results to a certain extent. A natural solution to this problem is calibration. Assuming stability of parameters during time, introducing the correction in, for example, resistance $R$, the systematic error can be entirely eliminated. Experimenting with different nominal values of $R_{0}$ revealed that the correction of $886 \Omega$, added to value of $10 \mathrm{k} \Omega$ of $R_{0}$, completely removes the systematic error. It is also convenient as, regardless of complexity of all parameter influences, only one correction appears to be sufficient.

Another experiment with the resistance $R$ in interval of $R=10.886(1 \pm 0.05) \mathrm{k} \Omega$ results in $e=0.0 \%$, associated with measurement uncertainty of $8.4 \%$.

A slight increase in uncertainty opens up a new question: how does the combined uncertainty depend on parameter uncertainties?

There are a few methods that can be used in solving the problem. One of them is based on the analysis of uncertainty in table form, called budget of uncertainty, shown in Table 2 .

Table 2. Uncertainty Budget for Example 2.

\begin{tabular}{|c|c|c|c|c|c|c|}
\hline Parameter & Estimate & Uncertainty & Distribution & Sensitivity & Contribution & Significance \\
\hline 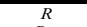 & $10.886 \mathrm{k} \Omega$ & $314 \Omega$ & Uniform & 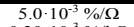 & $101.5 \%$ & \\
\hline & & $29 \mathrm{k} \Omega$ & Uniform & $0.30 \cdot 10^{-3} \% / \mathrm{k} \Omega$ & & \\
\hline$R_{2 \mathrm{x}}$ & $1.0 \mathrm{M} \Omega$ & $29 \mathrm{k} \Omega$ & Uniform & $0.30 \cdot 10^{-3} \% / \mathrm{k} \Omega$ & $9.0 \cdot 10^{-3} \%$ & \\
\hline & $1.0 \mu \mathrm{F}$ & $29 \mathrm{nF}$ & Uniform & $1.0 \cdot 10^{-6} \% / \mathrm{nF}$ & $30 \cdot 10^{-6} \%$ & \\
\hline$C_{1 x}$ & $1.0 \mathrm{pF}$ & $29 \mathrm{fF}$ & Uniform & $1.0 \cdot 10^{-6} \% / \mathrm{fF}$ & $30 \cdot 10^{-6} \%$ & \\
\hline$C_{2 \mathrm{x}}$ & $1.0 \mathrm{pF}$ & $29 \mathrm{fF}$ & Uniform & $1.0 \cdot 10^{-6} \% / \mathrm{fF}$ & $30 \cdot 10^{-6} \%$ & \\
\hline$\alpha_{1}$ & 1.0 & 0.014 & Uniform & 52 & $0.75 \%$ & * \\
\hline$\alpha_{2}$ & 1.0 & 0.014 & Uniform & -28 & $0.40 \%$ & * \\
\hline $\begin{array}{l}\alpha_{p} \\
\beta\end{array}$ & $\begin{array}{l}1.0 \\
1.0\end{array}$ & $\begin{array}{l}0.014 \\
0.014\end{array}$ & Uniform & 27 & $0.40 \%$ & * \\
\hline$\beta_{0}^{\beta}$ & $\begin{array}{l}1.0 \\
1.0\end{array}$ & $\begin{array}{l}0.014 \\
0.014\end{array}$ & $\begin{array}{l}\text { Uniform } \\
\text { Uniform }\end{array}$ & -28 & $\begin{array}{l}0.40 \% \\
0.56 \%\end{array}$ & * \\
\hline $\begin{array}{l}p_{p 1} \\
\beta_{p_{2}}\end{array}$ & 1.0 & $\begin{array}{l}0.014 \\
0.014\end{array}$ & $\begin{array}{l}\text { Unitorm } \\
\text { Uniform }\end{array}$ & $\begin{array}{l}39 \\
-28\end{array}$ & $\begin{array}{l}0.5 \% \% \\
0.40 \%\end{array}$ & \\
\hline $\begin{array}{l}\beta_{n 12} \\
\beta_{n 1}\end{array}$ & 1.0 & 0.014 & Uniform & $\begin{array}{l}-28 \\
13 \\
\end{array}$ & $\begin{array}{l}0.40 \% \\
0.20 \%\end{array}$ & * \\
\hline & $10.0 \mathrm{k} \Omega$ & $290 \Omega$ & Uniform & $-11 \cdot 10^{-3} \% / \mathbf{\Omega}$ & $3.3 \%$ & \\
\hline$R_{\mathrm{x} 2}$ & $10.0 \mathrm{k} \Omega$ & $290 \Omega$ & Uniform & $5.3 \cdot 10^{-3} \% / \Omega$ & $15 \%$ & $* *$ \\
\hline$R_{\mathrm{z}}$ & $1.0 \mathrm{M} \Omega$ & $29 \mathrm{k} \Omega$ & Uniform & $40 \cdot 10^{-3} \% / \mathrm{M} \Omega$ & $1.1 \cdot 10^{-3} \%$ & \\
\hline$C_{\mathrm{z}}$ & $1.0 \mathrm{pF}$ & $29 \mathrm{fF}$ & Uniform & $1.2 \cdot 10^{-6} \% / \mathrm{fF}$ & $33 \cdot 10^{-6} \%$ & \\
\hline$e$ & $\begin{array}{l}0.0 \% \\
\text { Combin }\end{array}$ & & & 4.2. & $4.2 \%$ & \\
\hline
\end{tabular}

In the first column, the parameters (their symbols) affecting the measurement error and uncertainty are enumerated.

Column two presents their nominal values. It was found by numerical experiments that for these parameter values, the error is very close to zero.
Column three shows standard uncertainties joined to the parameters, e.g., it was assumed that the resistance $R$ may yield values from the interval $10.886(1 \pm 0.05) \mathrm{k} \Omega$. The width of this interval is approximately $1089 \Omega$. Assuming the equal probability for any value from the interval (uniform probability distribution), standard uncertainty attached to $R$ equals $u(R) \approx 1089 /(2 \operatorname{sqrt}(3)) \Omega \approx 314 \Omega$. The same procedure was applied for all the parameters' standard uncertainties.

Column four shows that the uniform probability distribution is joined to all the parameters.

Column five provides the sensivity coefficients, showing how standard uncertainties, related to the parameters, affect the combined measurement uncertainty.

Column six gives the contributions to the combined measurement uncertainty, as the result of uncertainties of particular parameters.

The entries are calculated as products of absolute values in columns 3 and 4, helping to realize concequences of uncertainties of any parameter, which accounts for the application of uncertainty budget. It is obvious that great many parameters do not contribute to the combined uncertainty. Practically, owing to parameters $R, R_{x 1}$, and $R_{x 2}$, only three uncertainties are significant (marked by $* *$ in column 7). If all the uncertainties are neglected, except for the three above, the combined measurement uncertainty will be $8.0 \%$, instead of $8.4 \%$. This is entirely in agreement with the estimate made in Section 3 of this paper.

Considering the contributions resulting from the uncertainties of $\alpha_{1}, \alpha_{2}, \alpha_{p}, \beta, \beta_{p 1}, \beta_{p 2}$, and $\beta_{n 1}$, (marked by * in column 7), it appears that the entire amount of combined measurement uncertainty is reached.

Finally, the combined standard uncertainty (with $k=1$ ) was calculated as square root of sum of the sqares of values in column six, and the expanded uncertainty (with $k=2$ ) was the doubled value of combined standard uncertainty.

Conclusion: the capability to measure RMS of input signal in the proposed electronic device can be characterized by extended measurement uncertainty of approximately $8.5 \%$. It is assumed that proper calibration is needed so as to remove any systematic error.

\section{SIMULATION AND EXPERIMENTAL RESULTS}

To confirm the given theoretical analysis, the proposed current-mode bipolar RMS circuit in Fig.1. was simulated with the PSpice program. The CCCDTA and CCCIIs were realized by the schematic bipolar implementations given in Fig.3. and Fig.4., with the transistor model parameters of PR200N (PNP) and NP200N (NPN) of the bipolar arrays ALA400 from AT\&T [46]. The supply voltages and the values of the bias currents were $+V=-V=1.2 \mathrm{~V}$ and $I_{B I}=$ $I_{B 5}=100 \mu \mathrm{A}, I_{P}=300 \mu \mathrm{A}$, respectively, the input voltage being within the range of $0-500 \mathrm{mV}$.

Fig.9. shows the wave form of the signal at the output of the circuit shown in Fig.1. (voltage $V_{\text {out }}(t)$ ), whereby the total power dissipation was $5.80 \mathrm{~mW}$. Low power consumption of the proposed circuits results from applying low-voltage current mode and transconductance mode integrated circuits, with the use of bipolar transistor technique. Applying the current mode signal processing to solve the issues above is the right approach to the problem. 
However, similar and sometimes lower power consumption can be achieved using CMOS technology instead of the bipolar one.

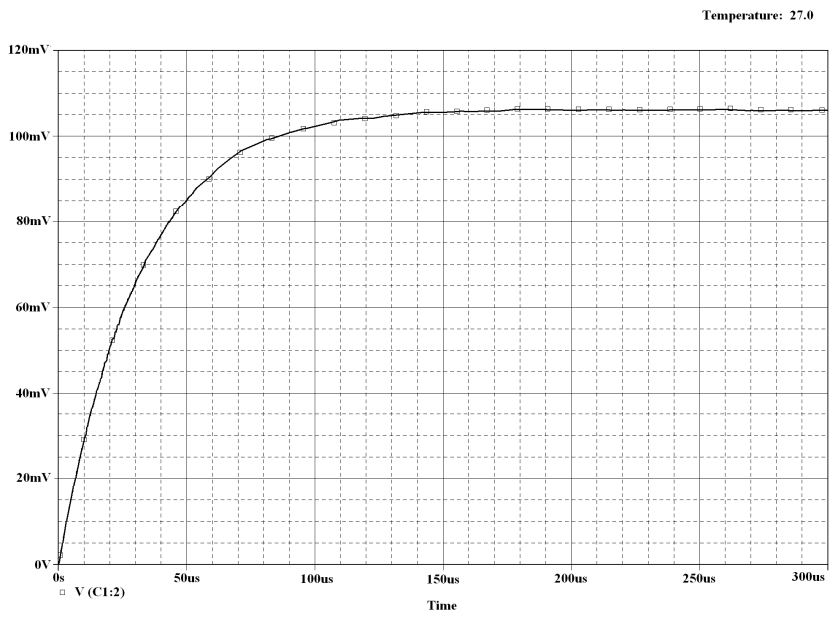

Fig.9. Time-domain response of the proposed RMS circuit for the sine input signal $\left(V_{\text {in }}(t)=150 \sin (2 \pi f t)[\mathrm{mV}], f=1 \mathrm{MHz}, \mathrm{R}=165 \Omega\right.$, $\mathrm{C}=0.2 \mu \mathrm{F})$.

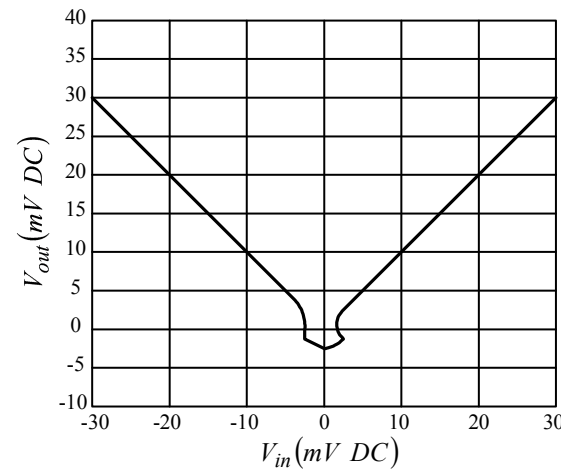

a)

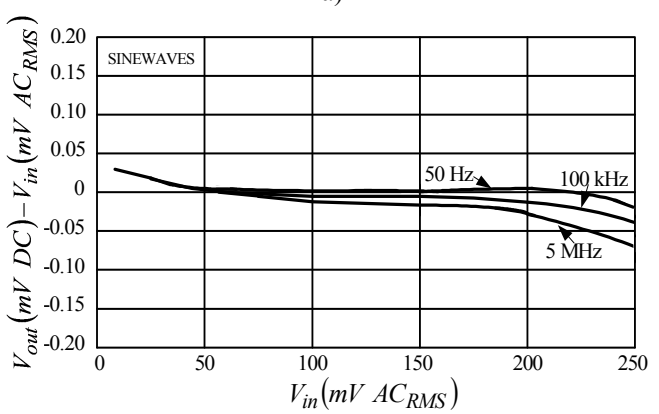

b)

Fig.10. a) DC transfer function near zero; b) AC linearity.

The output ripple is always considerably greater than the DC error; therefore filtering out the ripple can substantially reduce the peak error without long settling time penalty of simply increasing the averaging capacitor. The rippling of the output voltage generated in this manner is lower than in detector $[15,47]$, followed by the shorter feedback as well. Linearity may seem like an odd property for a device that implements a function that includes two very nonlinear processes: squaring and square rooting. However, an RMSto-DC converter has a transfer function, RMS volts in to DC volts out, that should ideally have a 1:1 transfer function. To the extent that the input to output transfer function does not lie on a straight line, the part is nonlinear. Fig.10.a) shows the DC transfer function nearing zero in the proposed circuit, while Fig.10.b) demonstrates the AC linearity of the RMS detector. The proposed detector circuit involves higher linearity compared to the ones described in $[15,16,47]$.

A common method to describe dynamic signal wave shapes is Crest Factor. It is the ratio of the peak value relative to the RMS value of a waveform. For example, a signal with a crest factor 4 has a peak four times its RMS value. The proposed circuit performs very well with crest factor 4 or less, and responds with reduced accuracy to signals with higher crest factors (Fig.11.). High performance with crest factors lower than 4 can be directly attributed to the high linearity throughout the proposed solution.

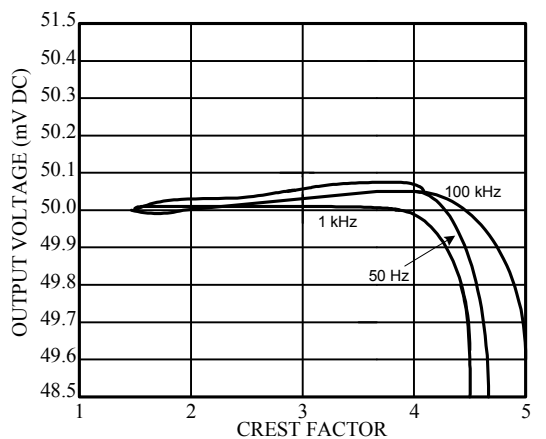

Fig.11. Performance vs. Crest Factor.

\section{Experimental results}

To validate practical operation of the proposed RMS to DC converter, the converter was constructed by employing commercial ICs. As the $R_{p}$ and $R_{n}$ do not affect the output signal, they can be ignored. For this reason, the MOCCCDTA can be implemented by using AD844 and LM13600, as displayed in Fig.12. [35]. The current differencing circuit and OTAs inside the MO-CCCDTA can be realized by using two AD844s and LM13600Ns, respectively.

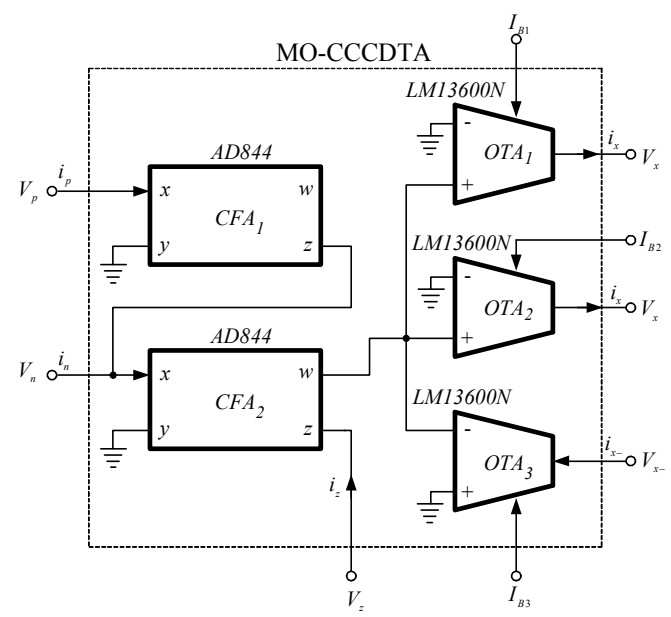

Fig.12. A possible implementation of MO-CCCDTA based on commercially available ICs. 
The CCCIIs can be constructed experimentally using AD844-type current conveyor (CCII+) IC of analogue devices [48]. To implement a CCII-, two CCII+ are used as proposed in [49]. External resistors of $1 \mathrm{k} \Omega$ are used instead of the intrinsic resistances, $R_{x l}$ and $R_{x 2}$. The test input signals were generated by using acquisition card NI ELVIS/PCI6251 Bundle (National Instruments). Power consumption of the tested circuit in Fig.12. was $4.36 \mathrm{~mW}$, while the whole experimental setup posed total power dissipation of $9.60 \mathrm{~mW}$. This is much bigger than for simulated circuits, which is also understandable considering the fact that discreet components were used in experiment setup.

Fig.13. shows the results of processing performed with the proposed converter with calibrated signals of different amplitude, frequency and waveform shape (single sine-tone, square and triangle signals), having a high crest factor (CF). For these input signals, in the described experimental setup, we used discrete resistors of $1 \%$ tolerance, and a polystyrene capacitor (e.g., for input signal of $5 \mathrm{MHz}$ frequency we use the resistor of $R=220 \Omega$ and capacitor of $C=0.5 \mu \mathrm{F}$ ). Fig.13. shows evaluation of measured data performed by comparing the simulation results (term exp. indicates experimental results, while sim. indicates simulation results).

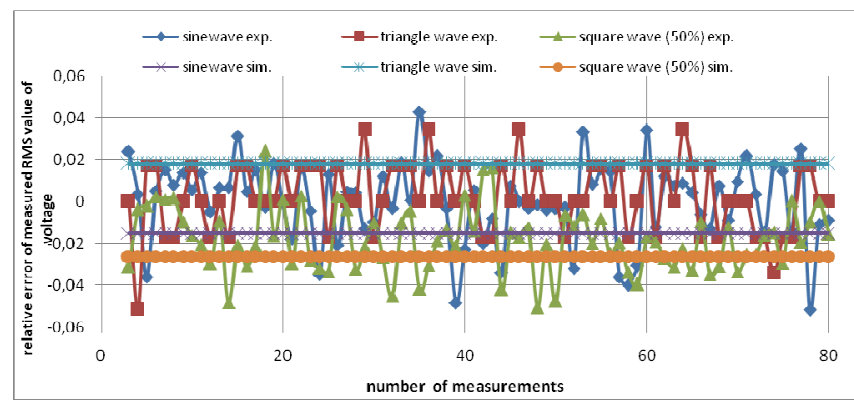

Fig.13. Experimental results.

The obtained results are considerably better than the ones obtained with RMS detectors described in [15, 17, 18]. During the experimental tests conducted in this manner, parallel measurements of RMS voltage were conducted using a highly precise multi-meter Fluke 5790A [50] (with reference with a metrology-grade meter), for the purpose of evaluating the possibilities to use the proposed circuits in real environment.

Fig.9. shows the results of pure sinusoid signals. However, as an RMS detector, the circuit should have consistent response in signals with equal powers but various waveform shapes. Thus, as in the case of simulation checks, the experimental setup responded to the single-tone sinusoid, two-tone signals, square-waves (duty cycle $=50 \%$ ) and triangle waves given in Fig.14. All the used signals were at $1 \mathrm{MHz}$. The relative errors were lower than $0.04 \%$ for $P_{i n} \leq-$ $20 \mathrm{dBm}$. In this manner, we can evaluate the measured data by comparing the simulation results. The presented results suggest a very good agreement between the simulated and experimental results.

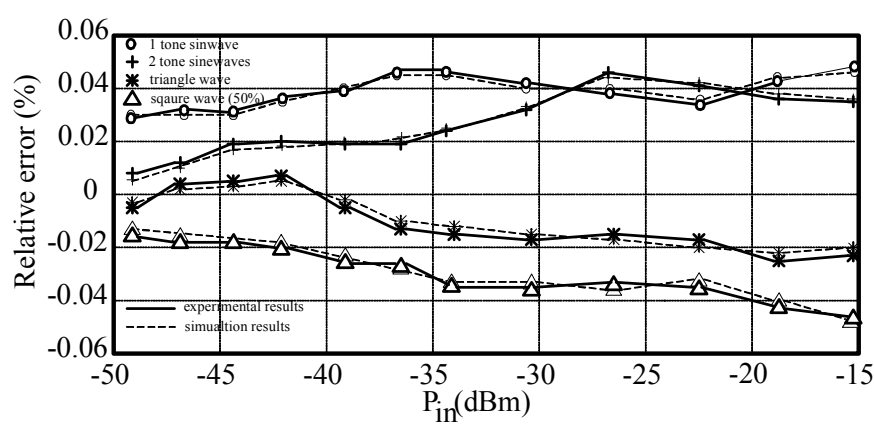

Fig.14. Comparison of the experimental results with simulated data of the proposed detector for various waveforms.

Given that the dynamic range has nonlinearity level lower than $1 \mathrm{~dB}$, the dynamic range of the circuit proposed in this paper is around $36 \mathrm{~dB}$.

The difference between the experimental and theoretical results may be due to the deviation of the design parameters, such as the $R, C$, and input impendence of the ICs used in the circuit, from the experimental values (due to the parasitic impedance effects of the AD844 elements).

The results above yield conclusion that the simulated and experimental results are in agreement with the theoretical analysis. Also, by changing the value of the external resistor used instead of $R_{x 2}$, we tested the tunability of the proposed RMS converter.

Based on the performances obtained, the proposed converter can be used for precise measurements of RMS value of $\mathrm{AC}$ signals in instrumentation, automatic gain control systems and analogue spectrum analyzers.

\section{CONCLUSION}

This paper reports on a new electronically controllable bipolar power converter. The proposed circuit employs two CCCIIs, one MO-CCCDTA and two grounded passive elements, which is advantageous from the integration standpoint. The proposed circuit ensures high precision, wide bandwidth and high accuracy. The results obtained by PSpice simulation imply that the maximum power consumption of the proposed converter is approximately $5.80 \mathrm{~mW}$ at $\pm 1.2 \mathrm{~V}$ supply voltages, respectively. The simulation and experimental results described are in agreement with theoretical expectations. The proposed circuit provides accurate RMS measurements over a frequency range of $50 \mathrm{~Hz}$ to $10 \mathrm{MHz}$, as well as for input voltage signals up to $500 \mathrm{mV}$. The real limit of precision $(0.04 \%)$ was obtained experimentally in laboratory environment.

\section{APPENDIX}

If the assumed input voltage signal is:

$$
v_{i n}(t)=\sum_{n=0}^{N} a_{n} \sin \left(n \omega t+\phi_{n}\right)
$$

Squaring such signal yields as follows: 


$$
\begin{aligned}
& v_{i n}^{2}(t)=\frac{1}{2} \sum_{n=0}^{N} a_{n}^{2}\left(1+\cos 2\left(n \omega t+\phi_{n}\right)\right)+\frac{1}{2} \sum_{\substack{n, m=0 \\
n \neq m}}^{N} a_{n} a_{m} \cos \left((n-m) \omega t+\phi_{n}-\phi_{m}\right) \\
& +\frac{1}{2} \sum_{\substack{n, m=0 \\
n \neq m}}^{N} a_{n} a_{m} \cos \left((n+m) \omega t+\phi_{n}+\phi_{m}\right)
\end{aligned}
$$

Incorporating the determined value of the input voltage signal into relation (12) renders the following:

$$
\begin{aligned}
& v_{\text {out }}^{2}(t)=\frac{2}{R C} \int_{0}^{t} e^{-2 \omega_{0}(t-\tau)} v_{\text {in }}^{2}(\tau) d \tau \\
& =\frac{1}{R C} \sum_{n=0}^{N} a_{n}^{2}\left(\int_{0}^{t} e^{-2 \omega_{0}(t-\tau)} d \tau+\int_{0}^{t} e^{-2 \omega_{0}(t-\tau)} \cos 2\left(n \omega \tau+\phi_{n}\right) d \tau\right)+ \\
& +\frac{2}{R C} \sum_{\substack{n, m=0 \\
n \succ m}}^{N} a_{n} a_{m}^{t} \int e^{-2 \omega_{0}(t-\tau)} \cos \left((n-m) \omega \tau+\phi_{n}-\phi_{m}\right) d \tau+ \\
& +\frac{2}{R C} \underset{\substack{n, m=0 \\
n \succ m}}{N} a_{n} a_{m}^{t} \int e^{-2 \omega_{0}(t-\tau)} \cos \left((n+m) \omega \tau+\phi_{n}+\phi_{m}\right) d \tau
\end{aligned}
$$

It follows that:

$$
v_{\text {out }}^{2}(t)=\frac{1}{R C} \sum_{n=0}^{N} a_{n}^{2}\left(I_{n, n}+J_{n, n}\right)+\frac{2}{R C} \sum_{\substack{n, m=0 \\ n \succ m}}^{N} a_{n} a_{m}\left(I_{n, m}+J_{n, m}\right)
$$

Whereby:

$$
\begin{gathered}
I_{n, m}=\frac{1}{4 \omega_{0}^{2}+(n-m)^{2} \omega^{2}}\left[\begin{array}{l}
-2 \omega_{0} \cos \left((n-m) \omega t+\phi_{n}-\phi_{m}\right) \\
+(n-m) \omega \sin \left((n-m) \omega t+\phi_{n}-\phi_{m}\right)
\end{array}\right] \\
-\frac{e^{2 \omega_{0} t}}{4 \omega_{0}^{2}+(n-m)^{2} \omega^{2}}\left[-2 \omega_{0} \cos \left(\phi_{n}-\phi_{m}\right)+(n-m) \omega \sin \left(\phi_{n}-\phi_{m}\right)\right] \\
\approx \frac{1}{4 \omega_{0}^{2}+(n-m)^{2} \omega^{2}}\left\{\begin{array}{c}
\omega_{0} \cos \left(\phi_{n}-\phi_{m}\right)\left[4 \omega_{0} t+\left((n-m)^{2} \omega^{2}+\omega_{0}^{2}\right) t^{2}\right. \\
-(n-m) \omega \sin \left(\phi_{n}-\phi_{m}\right)\left(1-\frac{\omega_{0}^{2} t^{2}}{2}\right)
\end{array}\right\} \\
I_{n, n}=\frac{1}{2 \omega_{0}}\left(e^{2 \omega_{0} t}-1\right)
\end{gathered}
$$

$$
\begin{aligned}
& J_{n, m}=\frac{1}{4 \omega_{0}^{2}+(n+m)^{2} \omega^{2}}\left[-2 \omega_{0} \cos \left((n+m) \omega t+\phi_{n}+\phi_{m}\right)+(n+m) \omega \sin \left((n+m) \omega t+\phi_{n}+\phi_{m}\right)\right]- \\
& -\frac{e^{2 \omega 0 t}}{4 \omega_{0}^{2}+(n+m)^{2} \omega^{2}}\left[-2 \omega_{0} \cos \left(\phi_{n}+\phi_{m}\right)+(n+m) \omega \sin \left(\phi_{n}+\phi_{m}\right)\right]
\end{aligned}
$$

$$
\begin{aligned}
& J_{n, n}=\frac{1}{2} \frac{1}{\omega_{0}^{2}+\omega^{2}}\left[-\omega_{0} \cos 2\left(n \omega t+\phi_{n}\right)+n \omega \sin 2\left(n \omega t+\phi_{n}\right)\right]- \\
& -\frac{1}{2} \frac{e^{2 \omega_{0} t}}{\omega_{0}^{2}+\omega^{2}}\left[-\omega_{0} \cos 2 \phi_{n}+n \omega \sin 2 \phi_{n}\right]
\end{aligned}
$$

(the approximation relative to $I_{n, m}$ was done using secondlevel $t$ polynomial, and a similar pattern can be applied in other relations). It follows that:

$$
v_{\text {out }}^{2}(t)=\frac{\left(1-e^{-2 \omega_{0} t}\right)}{\omega_{0} R C} V_{\text {true }-R M S}^{2}+R(t)
$$

Appendices, if needed, must appear before the acknowledgement.

\section{ACKNOWLEDGEMENTS}

The author wishes to thank the Ministry of Education and Science of the Republic of Serbia for their support to this work provided within the projects 42009 and OI-172057.

\section{REFERENCES}

[1] Northrop, R.B. (1990). Analog Electronics Circuits. Reading, MA: Addison-Wesley.

[2] Heavey, P., Whitney, C. (2004). RMS measuring principles in the application of protective relaying and metering. In 57th Annual Conference Protective Relay Engineering. IEEE, 469-489.

[3] Pogliana, U. (1997). Precision measurement of ac voltage below $20 \mathrm{~Hz}$ at IEN. IEEE Transactions on Instrumentation and Measurement, 46 (2), 369-372.

[4] Germer, H. (2001). High-precision AC measurements using the Monte-Carlo method. Transactions on Instrumentation and Measurement, 50 (2), 457-460.

[5] Yoon, W.-K., Deveney, M.J. (1998). Power measurement using the wavelet transform. Transactions on Instrumentation and Measurement, 47 (5), 1205-1210.

[6] Novotny, M., Sedlacek, M. (2008). RMS value measurement based on classical and modified digital signal processing algorithms. Measurement, 41 (3), 236-250.

[7] National Semiconductor Corporation. (2002). True RMS Detector. Application Note AN008474.

[8] Dataforth Corporation. (2011). DSCA33 Isolated True RMS Input Module. Application Note AN101.

[9] Analog Devices, Inc. (2011). High Precision, WideBand RMS-to-DC Converter. Application Note AD637.

[10] Mulder, J., Serdijn, W.A., Woerd, A.C., Roermund, A.H.M. (1996). Dynamic translinear RMS-DC converter. Electronics Letters, 32, 2067-2068.

[11] Mulder, J., Serdijn, W.A., Roermund, A.H.M. (1997). An RMS-DC converter based on the dynamic translinear principle. IEEE Journal of Solid State Circuits, 32, 1146-1150.

[12] Surakampontron, W., Kumwachara, K. (1999). A dual translinear-based RMS-to-DC converter. IEEE Transactions on Instrumentation and Measurement, 47, 456-464.

[13] Wasseneaar, R.F., Seevinck, E., Van Leeuwen, M.G., Speelman, C.J., Holle, E. (1998). New techniques for high-frequency RMS-to-DC conversion based on a multifunctional V-to-I convertor. IEEE Journal of Solid State Circuits, 23 (3), 802-815.

[14] Milanović, V., Gaitan, M., Bowen, E.D., Tea, N.H., Zaghlou, M.E. (1997). Thermoelectric power sensors for microwave applications by commercial CMOS fabrication. IEEE Electron Device Letters, 18 (9), 450452. 
[15] Petrović, P., Župunski, I. (2013). RMS detector of periodic, band-limited signals based on usage of DOCCIIs. Measurement, 46 (9), 3073-3083.

[16] Yu, C., Wu, C.L., Kshattry, S., Yun, Y.H., Cha, C.Y., Shichijo, H., Kenneth, K.O. (2012). Compact, high impedance and wide bandwidth detectors for characterization of millimeter wave performance. IEEE Journal of Solid State Circuits, 47 (10), 23352343.

[17] Kaewdang, K., Kumwachara, K., Surakampontorn, W. (2009). A translinear-based true RMS-to-DC converter using only npn BJTs. AEU - International Journal of Electronics and Communications, 63 (6), 472-477.

[18] Farshidi, E., Asiaban, H. (2012). A new true RMS-toDC converter using up-down translinear loop in CMOS technology. Analog Integrated Circuits and Signal Processing, 70 (3), 385-390.

[19] Zhou, Y., Chia, M.Y.W. (2008). A low-power ultrawideband CMOS true RMS power detector. IEEE Transactions on Microwave Theory and Techniques, 56 (5), 1052-1058.

[20] Yin, Q., Eisenstadt, W.R, Fox, R.M., Zhang, T. (2005). A translinear RMS detector for embedded test of RF ICs. IEEE Transactions on Instrumentation and Measurement, 54 (5), 1708-1714.

[21] Klahn, G. (1999). True RMS power detection with high dynamic range. In IEEE MTT-S International Microwave Symposium Digest, 13-19 June 1999. IEEE, vol. 4, 1773-1776.

[22] Zhang, T., Eisenstadt, W.R., Fox, R.M., Yin, Q. (2006). Bipolar microwave RMS power detectors. IEEE Journal of Solid State Circuits, 41 (9), 21882192.

[23] Yuce, E., Minaei, S., Tokat, S. (2007). Root-meansquare measurement of distinct voltage signals. IEEE Transactions on Instrumentation and Measurement, 56 (6), 2782-2787.

[24] Abulma'atti, M.T. (2009). Improved analysis of implicit RMS detectors. IEEE Transactions on Instrumentation and Measurement, 58 (3), 502-505.

[25] Lopez-Martin, A.J., Calosena, A. (2001). A currentmode RMS-DC converter for very low-voltage applications. In 8th IEEE International Conference on Electronics, Circuits and Systems, 2-5 September 2001. IEEE, vol. 1, 425-428.

[26] Koton, J., Herencsar, N., Vrba, K. (2011). Current and voltage conveyors in current and voltage-mode precision full-wave rectifiers. Radioengineering, 20 (1), 19-24.

[27] Taotao, Y., Hui, W., Jinbo, L., Jianjun, Z. (2013). A digitally calibrated CMOS RMS power detector for RF automatic gain control. Journal of Semiconductors, 34 (3), 1-7.

[28] Thanachayanont, A. (2014). Design of a low-power wide dynamic range CMOS RF power detector. International Journal of Electronics Letters, DOI:10.1080/00207217.2014.917717.
[29] Valdes-Garcia, A., Venkatasubramanian, R., Srinivasan, J., Silva-Martinez, R., Sánchez-Sinencio, E. (2005). A CMOS RF RMS detector for built-in testing of wireless transceivers. In 23rd IEEE VLSI Test Symposium, 1-5 may 2005. IEEE, 249-254.

[30] Kaewdang, K., Kumwachara, K., Surakampontorn, W. (2004). A simple wide-band CMOS based true rms-todc converter. International Journal of Electronics, 91 (7), 407-420.

[31] Farshidi, E., Sayedi, S.M. (2007). A micropower multi decade dynamic range current-mode true RMS-to-DC converter. In IEEE Northeast Workshop on Circuits and Systems (NEWCAS 2007), 5-8 August 2007. IEEE, 1493-1496.

[32] Shaterian, M., Twigg, C., Azhari, J. (2014). MTLbased implementation of current-mode CMOS RMSto-DC converters. International Journal of Circuit Theory and Applications, 43 (6), 793-805.

[33] Tangsrirat, W. (2007). Current-tunable current-mode multifunction filter based on dual-output currentcontrolled conveyors. AEU - International Journal of Electronics and Communications, 61, 528-533.

[34] Chien, H.C., Wang, J.M. (2013). Dual-mode resistorless sinusoidal oscilator using single CCCDTA. Microelectronics Journal, 44, 216-224.

[35] Silapan, P., Siripruchyanun, M. (2011). Fully and electronically controllable current-mode Schmitt triggers employing only single MO-CCCDTA and their applications. Analog Integrated Circuits and Signal Processing, 68 (1), 111-128.

[36] Silapan, P., Chanapormma, C. (2011). A temperatureinsensitive simple current-mode multiplier/divider employing only multiple-output CDTA, ACEEE. International Journal on Electrical and Power Engineering, 2 (3), 42-45.

[37] Lahiri, A., Chowdhury, A. (2011). Four quadrant analog multiplier using dual-current-controlled current differecing buffered amplifier. Journal of Circuits, Systems, and Computers, 20 (2), 223-231.

[38] Pisutthipong, N., Siripruchyanun, M. (2009). A novel simple current-mode multiplier/divider employing only single multiple-output current controlled CTTA. In TENCON 2009 - IEEE Region 10 Conference, 2326 January 2009. IEEE, 1-4.

[39] Tangsrirat, W., Pukkalanun, T., Mongkolwai, P., Surakampontorn, W. (2011). Simple current-mode analog multiplier, divider, square-rooter and squarer based on CDTAs. AEU - International Journal of Electronics and Communications, 65 (3), 198-203.

[40] Fabre, A., Saaid, F., Wiest, F., Boucheron, C. (1996). High frequency application based on a new current controlled conveyor. IEEE Transactions on Circuits and Systems I, 43 (2), 82-91.

[41] Minaei, S., Sayin, O.K., Kuntman, H. (2006). A new CMOS electronically tunable current conveyor and its application to current-mode filters. IEEE Transactions on Circuits and Systems I, 53 (7), 1448-1457. 
[42] Sotner, R., Slezak, J., Dostal, T., Petrzel, J. (2010). Universal tunable current-mode biquad employing distributed feedback structure with MO-CCCII. Journal of Electrical Engineering, 61 (1), 52-56.

[43] Frey, R. (2004). Exact analysis of implicit RMS converters. Electronics Letters, 40 (5), 1455-1456.

[44] Joint Committee for Guides in Metrology. (2008). Evaluation of measurement data - Guide to the expression of uncertainty in measurement. JCGM 100:2008.

[45] Joint Committee for Guides in Metrology. (2008). Evaluation of measurement data-Supplement 1 to the 'Guide to the expression of uncertainty in measurement' - Propagation of distributions using a Monte Carlo method. JCGM 101:2008.
[46] Frey, D.R. (1993). Log-domain filtering: An approach to currentmode filtering. IEE Proceedings G: Circuit Devices and Systems, 140, 406-416.

[47] Rumberg, B., Graham, D.W. (2012). A low-power magnitude detector for analysis of transient-rich signals. IEEE Journal of Solid State Circuits, 47 (3), 676-685.

[48] Analog Devices. (1990). Linear Products Data Book.

[49] Minaei, S., Yuce, E. (2008). Realization of tunable active floating inductance simulators. International Journal of Electronics, 95 (1), 27-37.

[50] Fluke, Inc. (2012). Fluke multimeters. http://us.fluke.com/usen/products/

Received March 09, 2015. Accepted July 30, 2015. 